\title{
LEVANTAMIENTO PLANIMÉTRICO DE LA CATEDRAL DE ÁVILA/ESPAÑA
}

\author{
(SURVEY OF THE CATEDRAL OF AVILA/SPAIN)
}

Marina Álvarez Alonso, Dra. Arquitecta (ICCET/CSIC)

Asunción Cámara Gómez, Arquitecta

$102-4$

M. Dolores Álvarez Alonso, Arqueóloga

ESPAÑA

Fecha de recepción: $27 \cdot$ VIII-91

RESUMEN

El levantamiento de planos por métodos diversos, entre los que se encuentra la metrología directa de campo, aporta importantes datos para la conservación y el control de los monumentos antiguos, a la vez que sirve de base para el conocimiento documental de la historia.

De esta forma, en este trabajo se publican los últimos levantamientos que, por encargo del Ministerio de Cultura, se realizaron de la Catedral de Ávila.
SUMMARY

Surveyng by divers methods, between direct metrology of the area may meet, apports important sources of information for the conservation and control of the monuments. This sources also serve for the documental history of the buildings.

On this way, the most recent surveys of Avila Cathedral are published in this paper. These surveys was realized by request of the Ministry of Culture.

Ficha técnica: Catedral de Ávila

Dimensiones: Longitud total del conjunto catedralicio

Ancho total del conjunto catedralicio

Ancho de la Catedral

Lado del patio claustrado

Superficie del patio claustrado $1.560,25 \mathrm{~m}^{2}$

\section{Cronología constructiva}

S.XI 1091-1107 - Primera atribución de la Catedral a Casandro, Florín de Pituerga y Alvar García.

S.XII-XIII - Primitiva fábrica del templo.

S.XIV $1307 \quad-$ Construcción del brazo norte.

S.XIV 1312-1355 - Construcción del brazo Sur y resto del brazo mayor.

S.XIV $\quad-$ Cerramiento de las bóvedas.

S.XIV $\quad-$ Claustro gótico.

S.XV 1432 - Finalización de la Catedral.

S.XVI $1595 \quad$ - Iniciación de la capilla de San Segundo.

S.XVII $1615 \quad-$ Terminación de la capilla de San Segundo. 


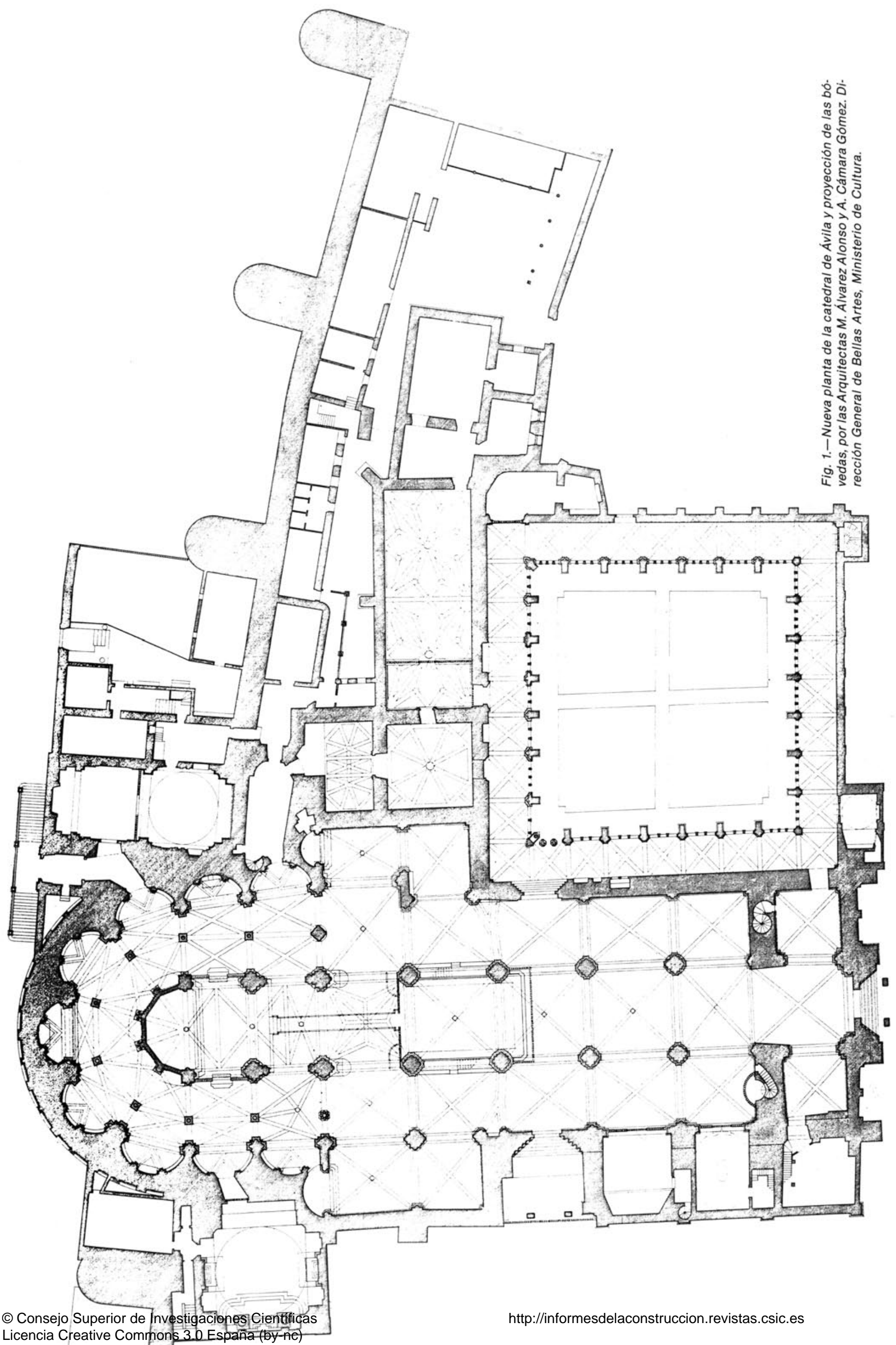




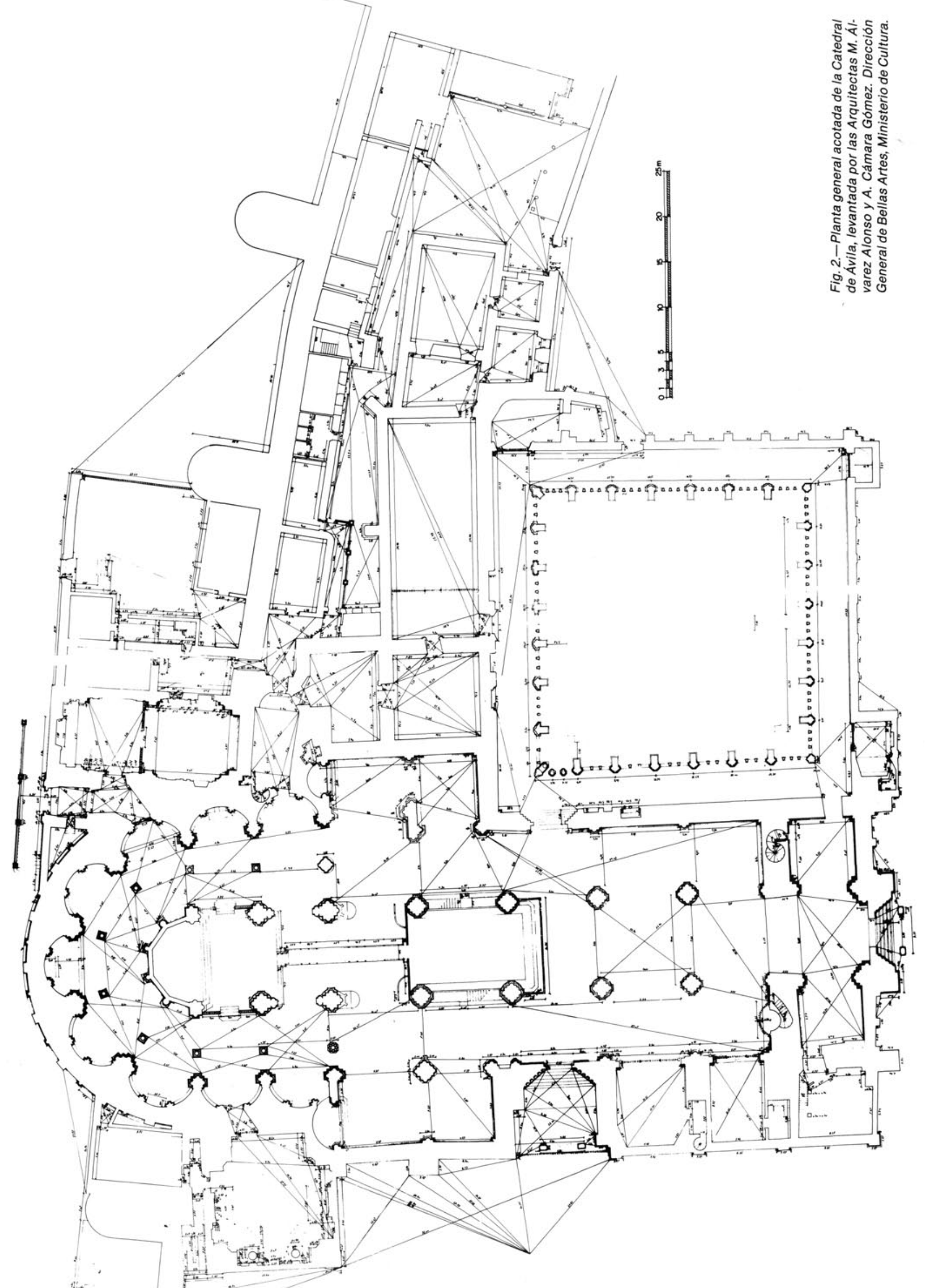
Liçencia Creative Commons 3.0 España (by-nc) 


\section{PLANIMETRÍA DE LA CATEDRAL}

La planimetria de la catedral de Ávila fue encargada por la Dirección General de Bellas Artes del Ministerio de Cultura, en 1983. El levantamiento fue llevado a cabo por los arquitectos Marina Álvarez, Asunción Cámara, Álvaro Caruana, Adelaida Esteve, Zósimo García y la Arqueóloga M. Dolores Álvarez. La supervisión del trabajo correspondió al arquitecto Merino de Cá. ceres.

El levantamiento fue realizado por superposición de metodologias: mecánica, triangulación y longitudinal. Los documentos originales elaborados a escala 1:100 han finalizado en 2 planos de planta (figs. 1 y 2). Para llegar a estos planos se realizaron, también a escala 1:100, todas las pilastras y pilares, incluyendo claustros y capillas, habiéndose realizado asimismo las pro- yecciones sobre la planta de bóvedas y la traza del coro.

El levantamiento de los planos conlleva gran interés para la restauración y conservación del monumento, así como su comportamiento ante las posibles patologías por las que se puede ver afectado.

\section{HISTORIA DE LA CATEDRAL}

La Catedralidad de Ávila se remonta a los primeros tiempos del cristianismo, y se supone fundada en Abula por San Segundo, siendo sufragánea de la de Mérida para después pasar a serlo de la de Santiago de Compostela. El episcopólogo abulense se reanuda en el siglo VII con Justiniano y poniendo fin a la catedralidad la invasión musulmana. Ésta será instaurada de nuevo por Alfonso VI adquiriendo, de nuevo, su anti-

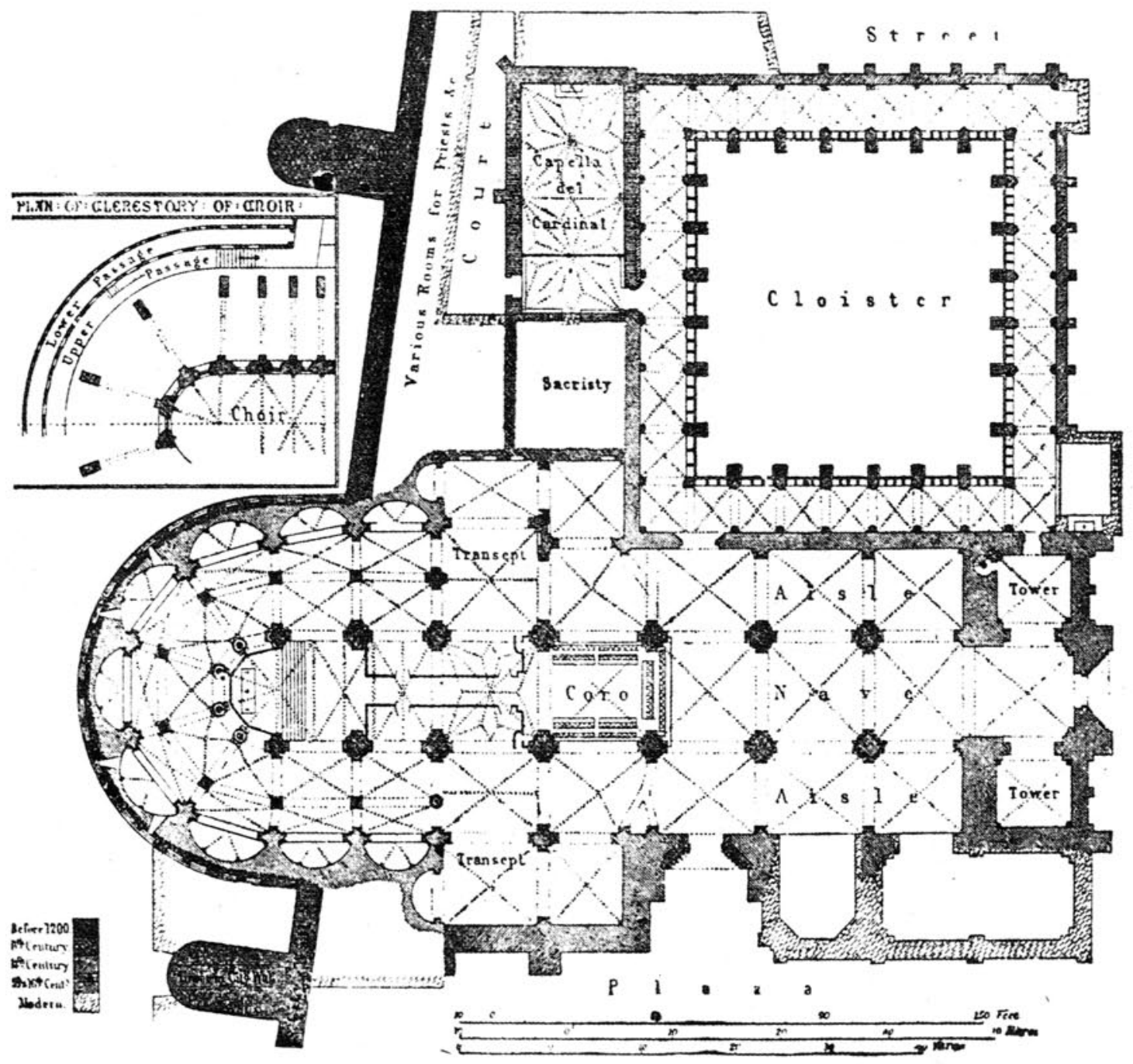

Fig. 3.-Planta de street publicada en "La Arquitectura gótica en España”, 1865.

Equivalencia castellana de los términos ingleses que aparecen en esta lámina:

Aisle = nave lateral; Cloister = claustro; Transept = transecto; Sacristy = sacristia; Tower = torre; Choir = coro; Court = patio; Capella de Cardinal = capilla del Cardenal. 
gua dignidad, que fue creciendo en importancia a la vez que la ciudad.

La construcción de la catedral se llevó a cabo en torno a los años 1091 y 1107 (fig. 3), años en los que Ramón de Borgoña restauraba la ciudad. Su construcción se atribuye a varios maestros: Casandro, Florín de Pjtuerga y Alvar García. Pero lo cierto es que la primitiva traza del templo no parece anterior a los últimos años del siglo XII o principios del XIII, atribuyéndose su levantamiento, o al menos su intervención en la cabecera, a un maestro llamado Fruchel del que no se sabe apenas nada.

La obra continuó por el brazo del crucero en el siglo XIV: en 1307 se construye el brazo Norte, y entre 1312 y 1355 el obispo D. Sancho Blázquez Dávila construye el brazo Sur, y acaso el resto del brazo mayor. Puede suponerse, por los arcos formeros que arrancan directamente de los pilares del brazo mayor, que las obras continúan durante el siglo XIII, cerrándose las bóvedas en el siglo XIV y finalizando en el siglo XV con algunas adiciones y reformas. De su término queda constancia en una bula expedida por el papa Eugenio IV en 1432, en la que se comenta acerca de su conservación, lo que quizá debiera interpretarse como fin de su construcción.

\section{ANÁLISIS DE LA CATEDRAL}

En la catedral de Ávila se distinguen dos momentos constructivos de distinta escuela, que se corresponden a dos partes diferenciadas: 1 i.) la cabecera hasta la nave del crucero, de transición románico ojival; y 2 .) el brazo mayor y el brazo del crucero, que corresponden al apogeo del estilo.

La cabecera o ábside, un enorme cubo saliente de la muralla, oblícuamente encajado en la parte oriental de ésta, hace de la iglesia un ejemplo de arquitectura religioso-militar. La diferencia de fábrica, de mampostería a espejo en la muralla y de silleria en la catedral, así como el sistema de barbacana corrida, de origen normando y diferente al romano de la muralla, señalan la posterioridad de la cabecera respecto a la muralla.

Dentro del cubo semicircular o "cimorrio" se encuentra la cabecera de la catedral, compuesta de una capilla mayor con doble deambulatorio y capillas absidales, que vacian el grueso de la muralla. Los apoyos interiores son monocilindricos y compuestos, los intermedios de la girola columnas y los del recinto exte. rior, también compuestos, con núcleo prismático y columnitas en los frentes (fig. 4). Los arcos son apuntados de perfil rectangular o de gruesos vaquetones $y$ de medio punto en las ventanas.

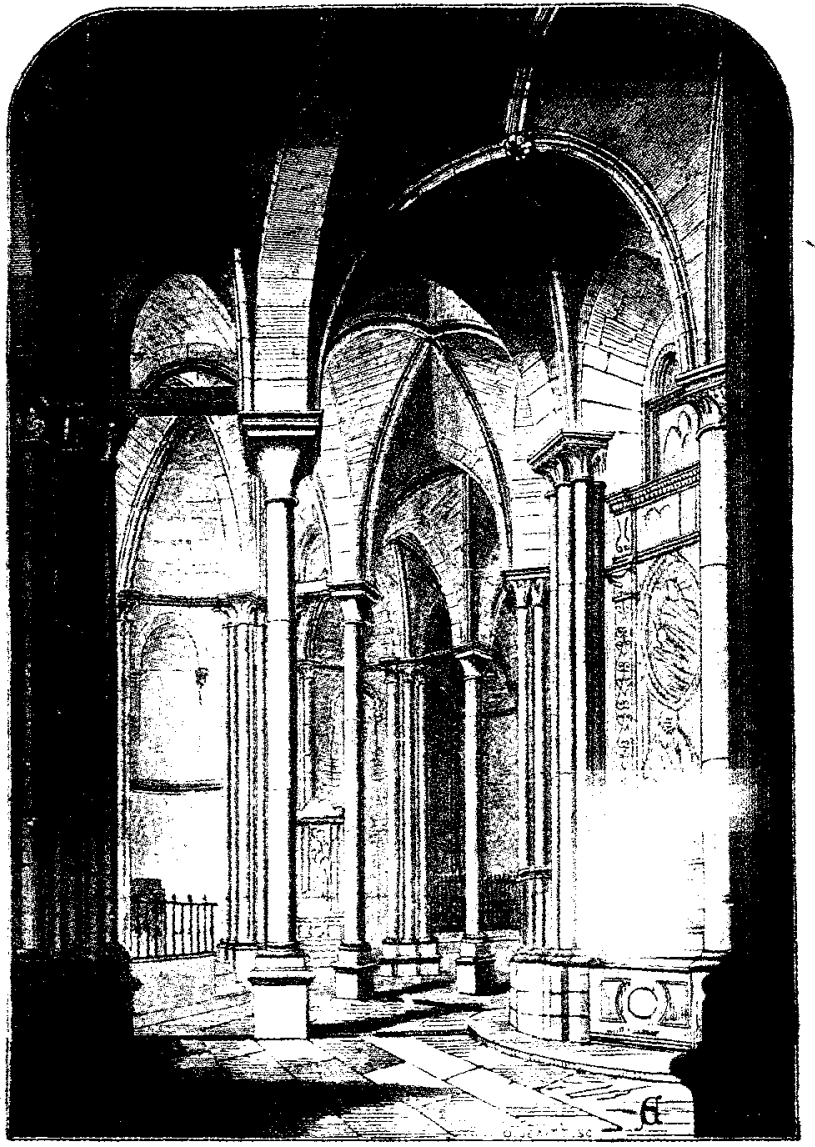

Fig. 4.-Interior de la Girola.

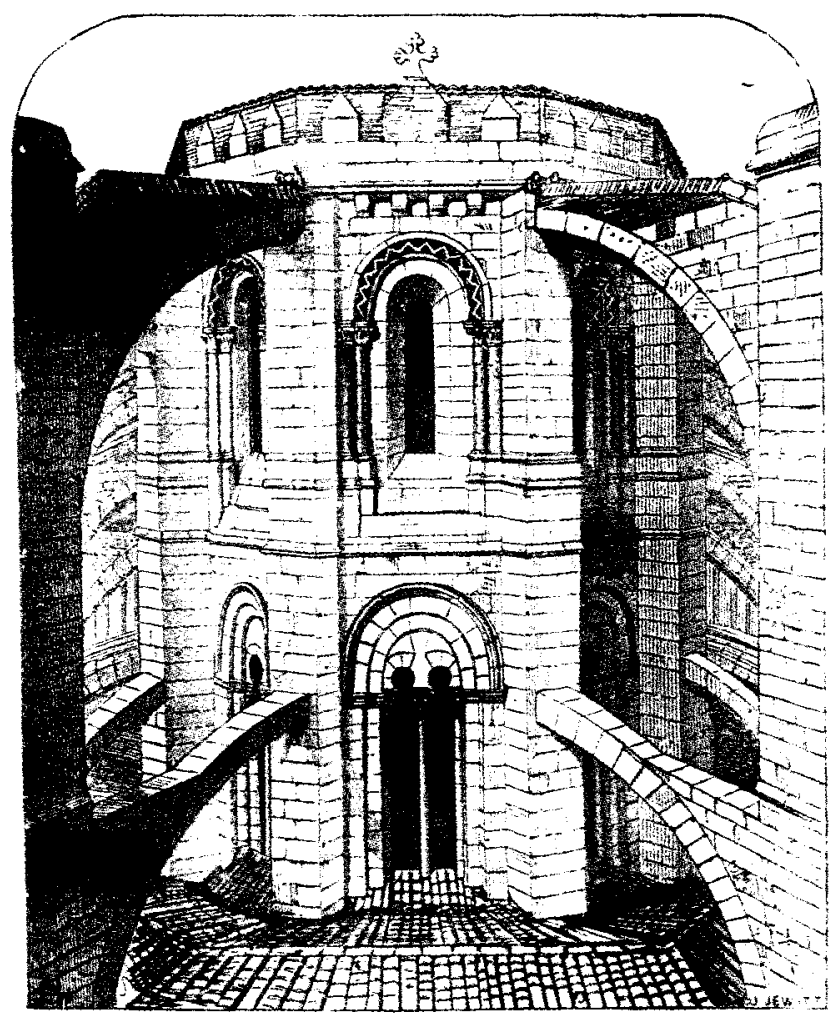

Fig. 5.-Exterior de la Capilla Mayor. 


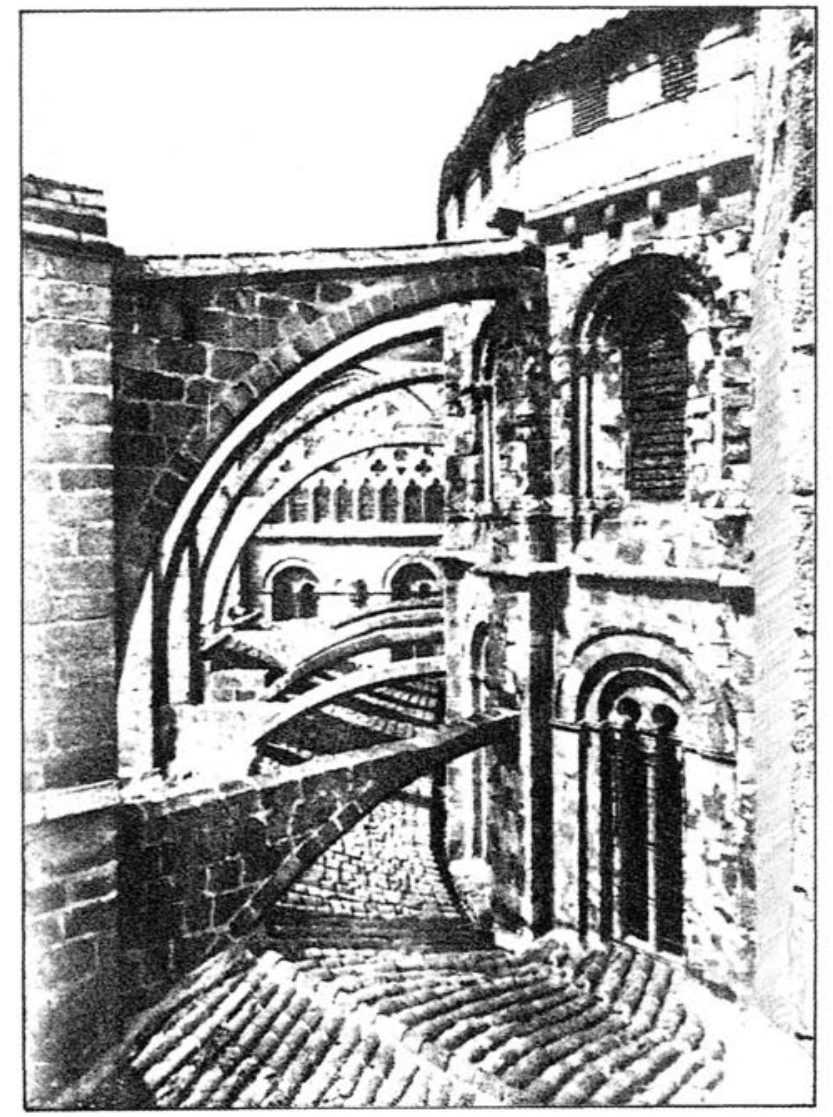

Fig. 6.-Ventanas de la cabecera de la Catedral.

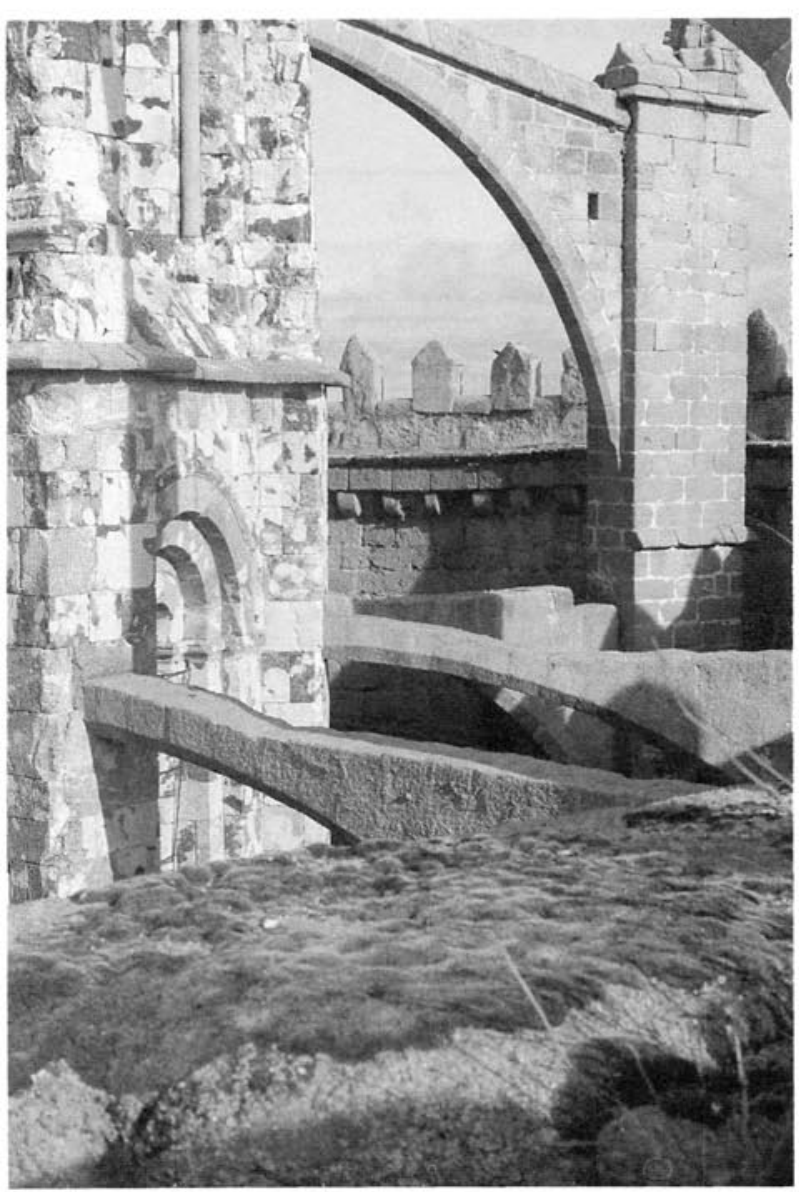

Foto 1. Cabecera de la catedral.
La presencia de girola doble en iglesias de tres naves, es un caso único en iglesias de transición en España. Se han barajado varias explicaciones para este hecho: la más acertada parece ser la de Lamperez (5), que atribuye esta singularidad a la necesidad de disponer de un gran recinto para las tropas, de ahí la conveniencia de dividir en dos tramos el deambulatorio, con cuya anchura resultarian prolongados los espacios trapezoidales de la girola y se aumentaban las dificultades de cubrir con una sola bóveda de crucería.

Las capillas absidales responden a la necesidad de aligerarse la masa del muro en que están embutidas, siendo esto frecuente en la poliorcética de los siglos XII y XIII. Por otro lado, como expone Lamperez, desde el punto de vista religioso se impone este sistema, ya que no son admisibles los salientes, por ser el ábside abulense un cubo de la muralla.

El abovedamiento de la girola es de crucería trapezoidal. Las capillas están cubiertas o bien con casquetes esféricos sobre nervios que concluyen en la clave del arco de cabecera, o bien en crucerías de disposición análoga.

La capilla mayor presenta dos órdenes de ventanas: de vanos ajimezados, con dos columnitas y dos arquillos de herradura, bajo otro arco mayor del mismo estilo o de medio punto (fig. 5).

La capilla mayor aparece cubierta con bóvedas de crucería sexpartita, cargando los tramos sobre seis apoyos, dos de ellos falsos, que suben desde las claves de los formeros de las naves laterales.

Exteriormente el cubo está seccionado verticalmente por fajas angulares que suplen los contrafuertes y coronado por dos recintos de barbacanas. A su vez sobre la capilla mayor se levanta un tercer recinto almenado (fig. 6, foto 1). El cuerpo alto de la cabecera tiene doble bateria de arbotantes, fechados en el siglo XV, a fin de contrarrestar las crucerías de la capilla mayor.

Determinadas circunstancias de la existencia de éstos han permitido especular sobre la existencia de un triforio hoy desaparecido. La existencia de éste viene dada por los siguientes criterios: a) un muro bajo el techo que sigue la línea poligonal exterior de la girola (foto 2), con unas ménsulas semirrománicas a modo de salmeres de arcos fajones de cuarto de circunferencia; b) que dan al muro de la capilla mayor; c) la zona de apoyo de un cañón seguido existente en el muro. 
Informes de la Construcción, Vol. 43 n.॰ 416, noviembre/diciembre, 1991

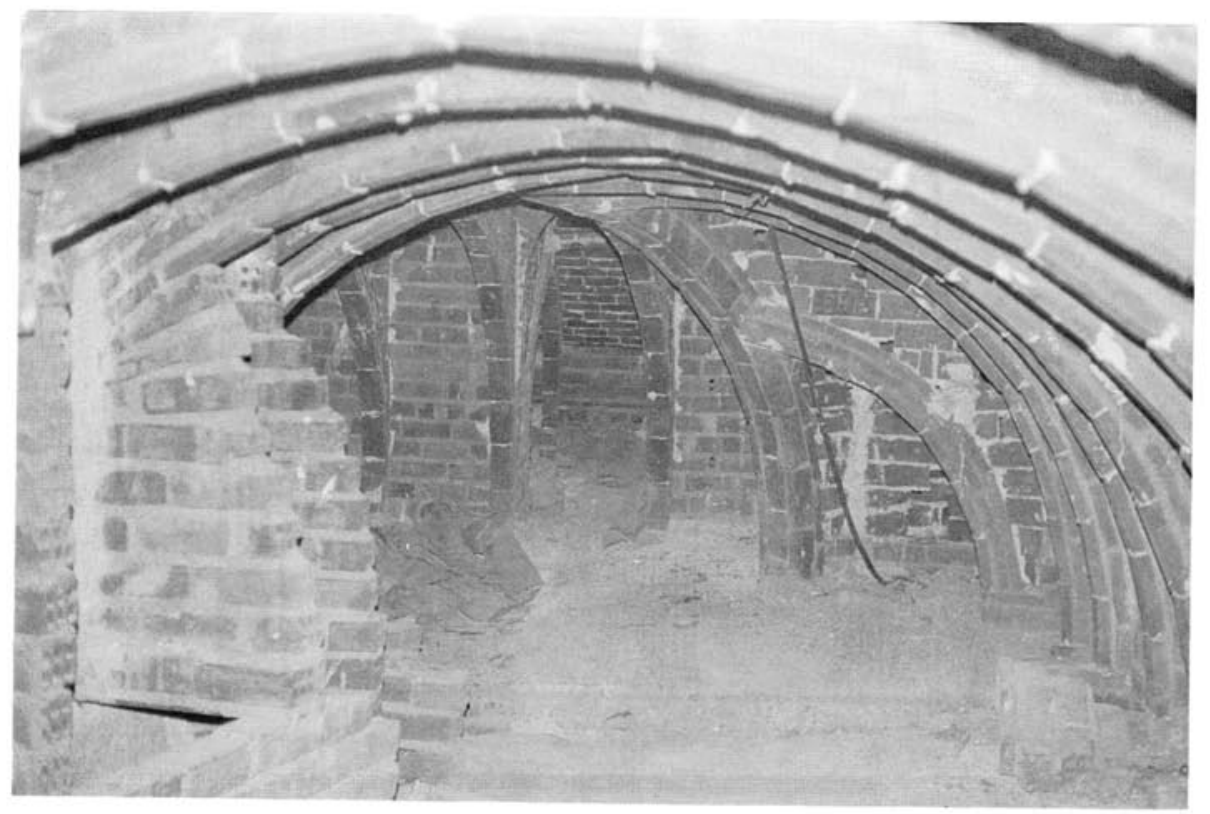

Foto 2. Cubierta bajo el techo.

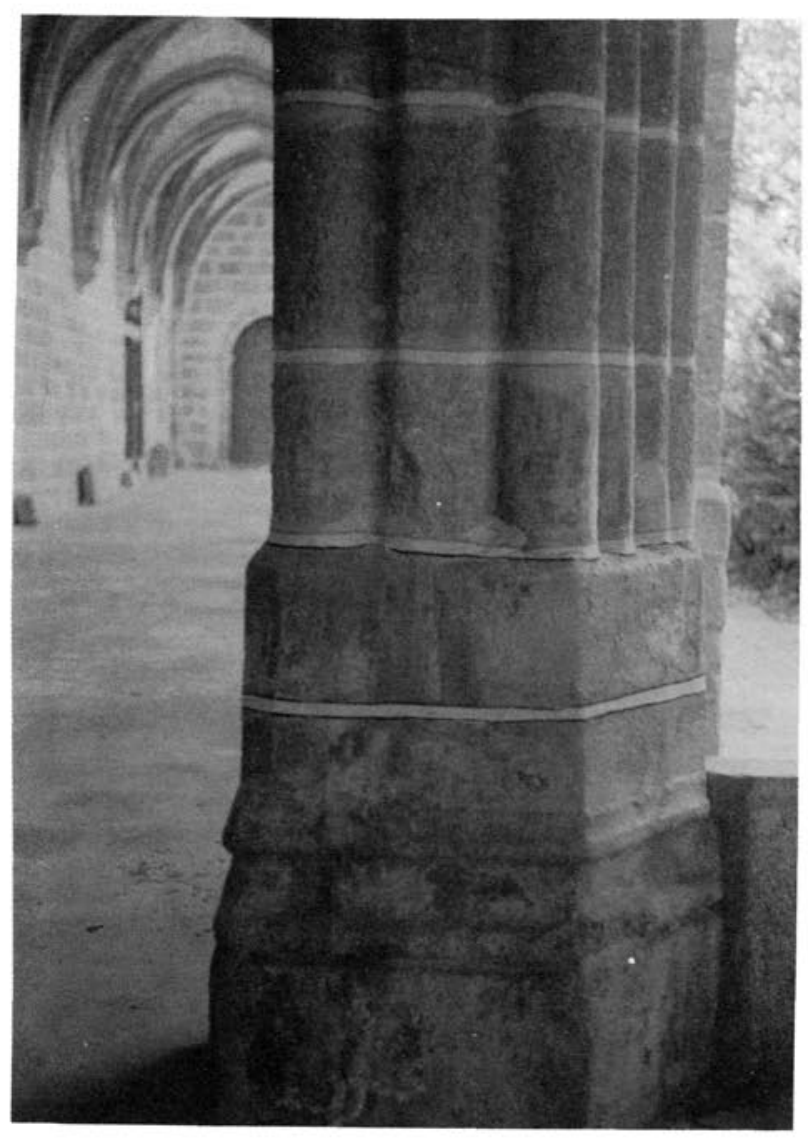

Foto 3. Pilar de núcleo prismático y columnas en sus frentes.

(c) Consejo Superior de Investigaciones Científicas Licencia Creative Commons 3.0 España (by-nc)

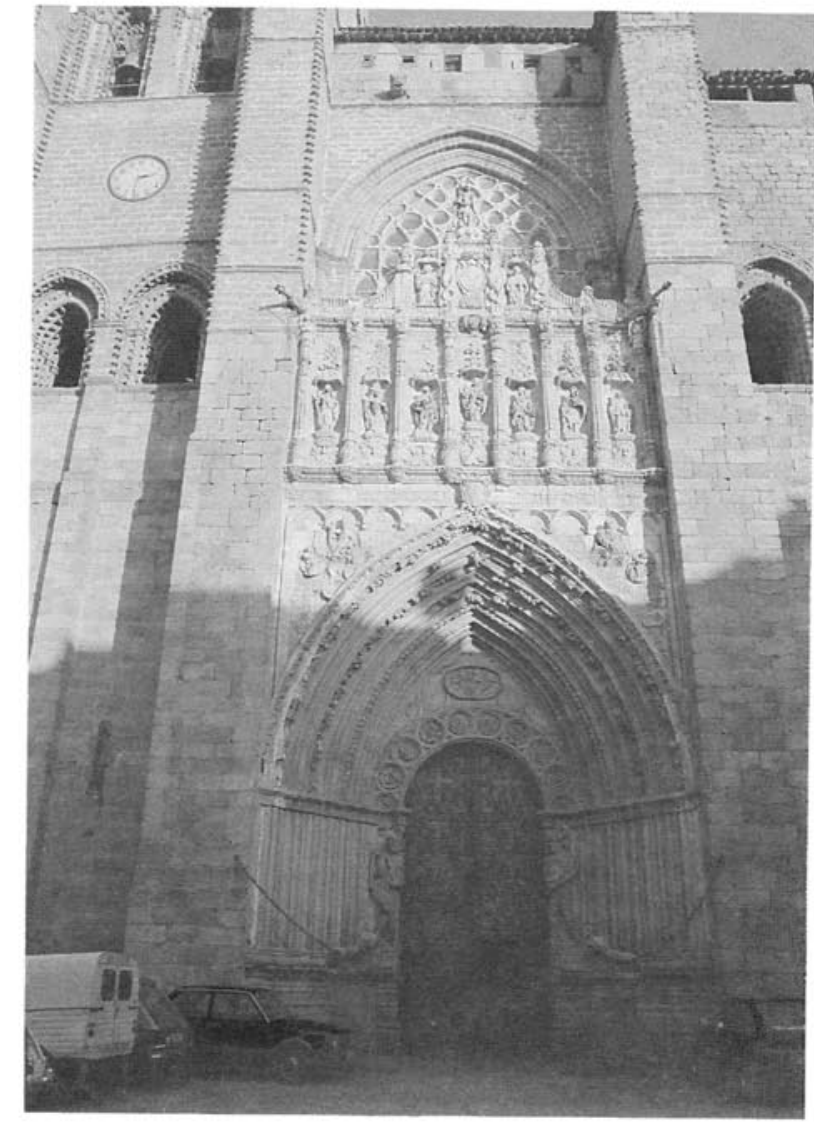

Foto 4. Fachada principal.

http://informesdelaconstruccion.revistas.csic.es 


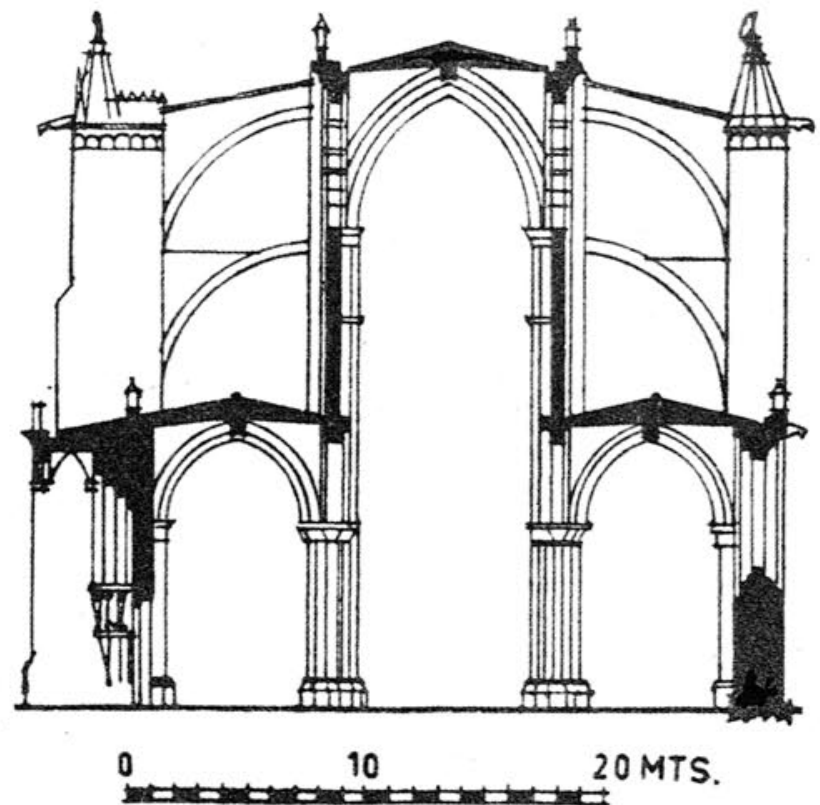

Fig. 7.-Sección de la Catedral.

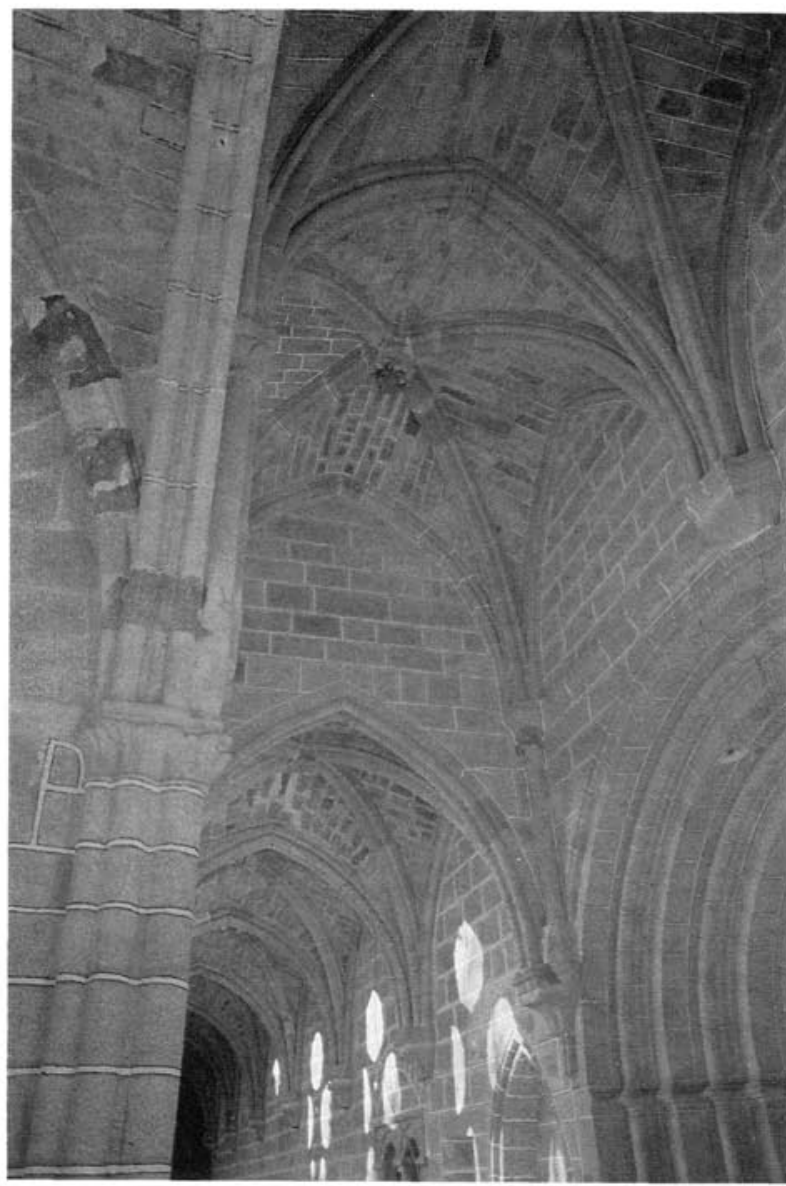

Foto 5. Bóvedas del claustro gótico.

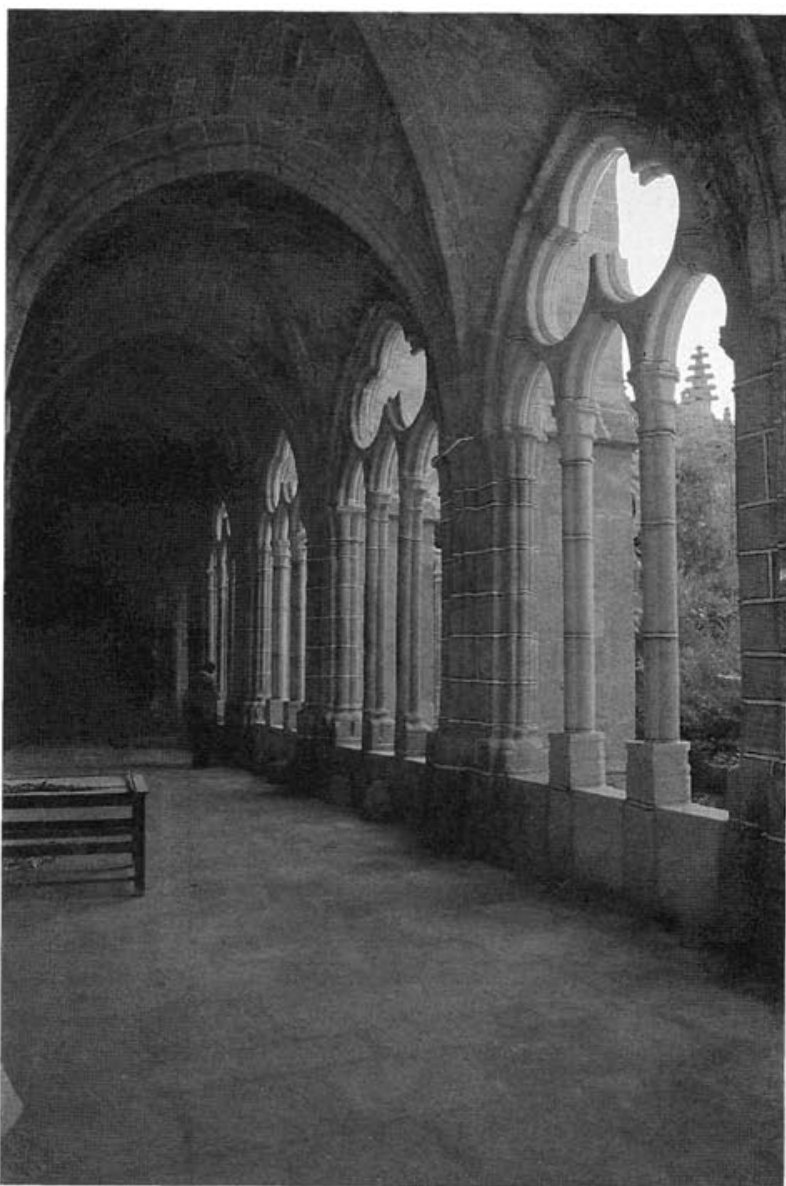

Foto 6. Crestería del claustro.

http://informesdelaconstruccion.revistas.csic.es 
En lo que se refiere a la 2. parte de la catedral, en el brazo mayor se observan cambios de estilo; así los tramos continuos al crucero tienen la disposición del triforio y bóveda sexpartita y en los extremos el triforio ha desaparecido y las bóvedas son de cruceria común. El estilo se vuelve ojival, a pesar de los pilares de núcleo prismático y columnas en sus frentes (foto 3 ).

Del brazo mayor arrancan tres naves (fig. 7 ): las laterales se encuentran con la del crucero en arcos apuntados, en los que la zona correspondiente al triforio se une con la alta que ocupa el espacio entre pilares, bóvedas de crucería y dobles arbotantes.

Las dos torres de la fachada principal parecen parte del sistema de fortificación, ya que se comunicaban con el ábside por doble recinto cubierto. Entre estas dos torres hay una zona abovedada que forma parte de la nave mayor, aunque no comunicada con las naves laterales; esto permite afirmar la posterioridad de la fachada principal (foto 4). La primitiva disposición de ésta, constituía un nártex entre las dos torres con la portada al fondo de éste y un paso sobre ella.

En el tramo contiguo al crucero, ubicado en la nave central, se encuentra el coro perteneciente al estilo plateresco. Fue encargado a Cornelio de Holanda en 1535 , trabajando en los relieves de las sillerías, asi como en el transcoro se encargó a Juan Rodriguez y Lucas Giraldo.

En el lado sur del brazo central se encuentra el claustro de estilo gótico (foto 5), construido en el siglo XIV con crestería renacentista (foto 6), a él se abre la capilla del Cardenal.

Aneja a la catedral se encuentra la capilla de San Segundo iniciada en 1595, con proyecto de Francisco de Mora, edificada a instancia del obispo Don Jerónimo Manrique de Lara, cuya terminación se fecha en 1615.

\section{BIBLIOGRAFÍA}

1) Alcolea, S., "Ávila monumental", Madrid 1952.

2) Fernández Casanova, A., "La Catedral de Ávila”, Madrid 1914.

3) González, N., Sobrino, T., "La Catedral de Ávila", León 1981.

4) Tormo Monzó, E., "Ávila" Cartilla Excursionista, Madrid 1918.

5) Lamperez, V., "Historia de la arquitectura cristiana española", Madrid 1930.

6) Chueca Goitia, F., "Historia de la arquitectura española", Edad Antigua y Edad Media, Madrid 1965.

7) Street, G.E., "La Arquitectura gótica en España”, Madrid 1865.

\section{publicación del ICCET/CSIC}

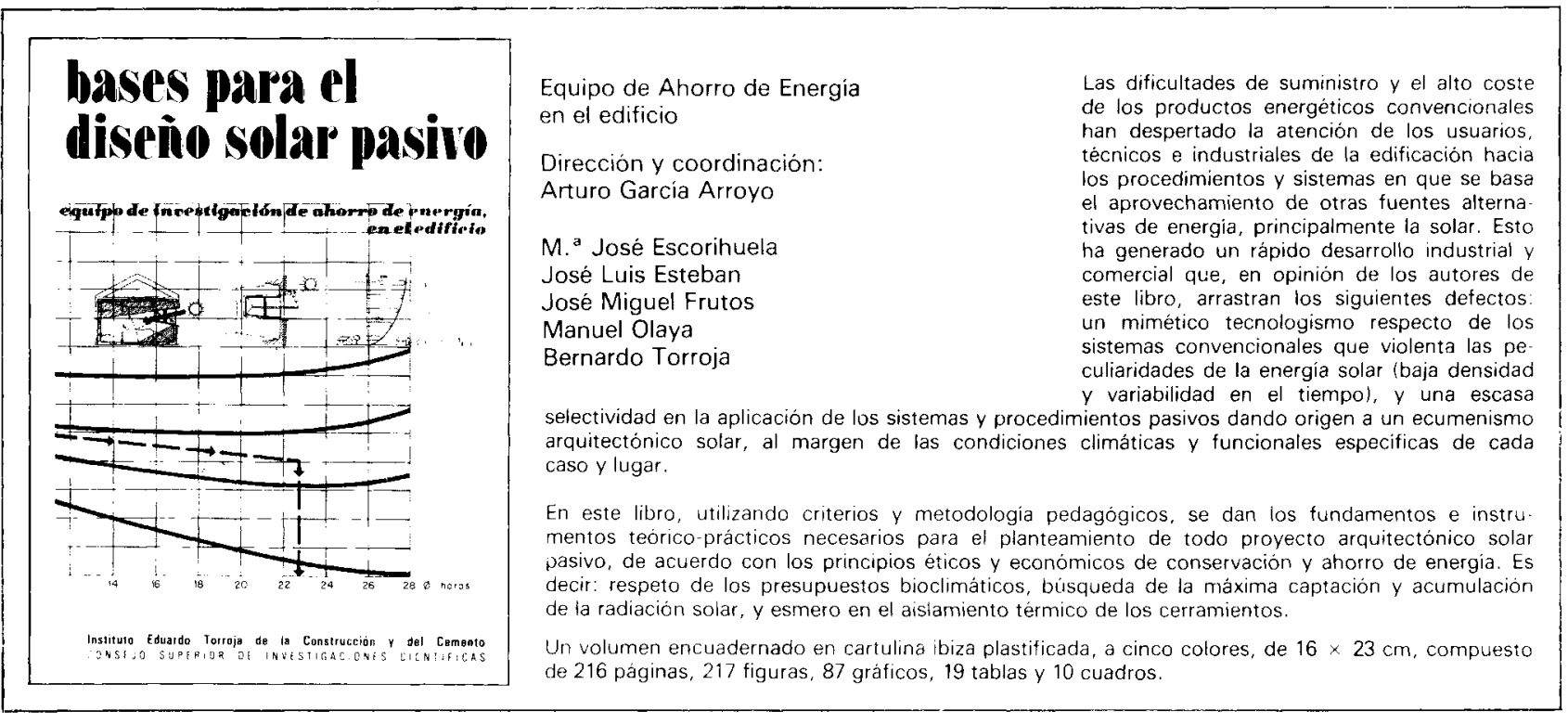

